\title{
Videoconferências em tempos de COVID- 19: reflexões para o contexto educacional
}

\author{
Videoconferences in times of COVID-19: reflections for the \\ educational context
}

\section{Videoconferencias en tiempos de COVID-I9: reflexiones para el} contexto educativo

\author{
Guilherme Mendes Tomaz dos Santos' \\ https://orcid.org/0000-000I-9086-669X
}

\begin{abstract}
Resumo: $O$ ensaio, de natureza qualitativa, teve por objetivo refletir sobre as potencialidades das videoconferências frente à pandemia da COVID-19 no âmbito educacional. Para tanto, contextualiza o Brasil no cenário pandêmico e reflete sobre as tecnologias digitais, em especial a videoconferência, como ferramentas auxiliares ao processo de ensino-aprendizagem e sobre dinâmicas para a "nova normalidade educativa". Destaca a copresença como um fator positivo e emergente dessa nova realidade, em que se pode ser mais bem explorada na formação discente nas diferentes etapas educativas e na minimização da distância entre o presencial e o virtual. Contudo, ressalta a necessidade da promoção de melhores condições de acessibilidade aos estudantes, em especial aos vinculados à rede pública, buscando promover maior equidade em suas trajetórias formativas.
\end{abstract}

Palavras-chave: Educação. Tecnologias digitais. Ensino-aprendizagem.

Abstract: The rehearsal, of qualitative nature, had for goal reflect about the potentialities of videoconferences front to COVID-19 pandemic in the educational field. Therefore, contextualizes Brazil in the scenery pandemic and reflects about the digital technologies, especially for videoconference, like auxiliary tools to the teaching learning process and about dynamics for the "new educational normality." highlights as a positive and emerging factor of this new reality in which it can be more explored in student training in the different educational stages and in minimization of the distance between essential and the virtual. However, it emphasizes the need to promote better accessibility conditions for students, especially to the entailed to the public school, seeking to promote larger equity in their training trajectories.

Keywords: Education. digital technologies. Teaching-learning.

Resumen: El ensayo es de naturaleza cualitativa, el objetivo es reflexionar sobre las potencialidades de las videoconferencias ante a la pandemia de la COVID-19 en el ámbito educativo. Se contextualiza en Brasil dentro del escenario pandémico y reflexiona sobre el uso de las tecnologías digitales en especial el uso de las

\footnotetext{
I Pós-doutorando em Educação pela Universidade Federal do Rio Grande do Norte (UFRN). Bolsista PNPD/CAPES. Doutor em Educação pela Universidade La Salle (UNILASALLE) com período sanduíche na Universidade La Salle México (ULSA). Professor Substituto da Educação Básica, Técnica e Tecnológica (EBTT) do Núcleo de Educação da Infância do Colégio de Aplicação da Universidade Federal do Rio Grande do Norte (NEI/CAp/UFRN). Mor de Comando da Banda Musical Morada do Vale (BMMV/Gravataí/RS). E-mail: mendes.guilherme234@gmail.com
}

Olhar de professor, Ponta Grossa, v. 24, p. I-9, e-I 5857.047, 202 I.

Disponível em <https://revistas2.uepg.br/index.php/olhardeprofessor> 
videoconferencias, como herramientas auxiliares al proceso de enseñanza-aprendizaje y sobre todo de las dinámicas para la "nueva normalidad educativa". Destaca la copresencia como un factor positivo y emergente de esta nueva realidad en la que se puede explorar en la formación discente en las diferentes etapas educativas y en la minimización de la distancia entre lo presencial y lo virtual. Sin embargo, es imperante la necesidad de la promoción de mejores condiciones de accesibilidad a los estudiantes, en especial a los vinculados en la red pública, buscando promover una mayor equidad en sus trayectorias formativas.

Palabras-clave: Educación. Tecnologías digitales. Enseñanza-aprendizaje.

\section{Introdução}

No transcurso do final de 2019 para o início de 2020, a população mundial viu-se acometida de uma nova pandemia que modificou, abruptamente, as atuais configurações das relações socioculturais, econômicas, geopolíticas e sanitárias, impondo o distanciamento social como alternativa para a redução da disseminação viral e da mortalidade ocasionada pelo novo coronavírus - COVID19. A patologia é uma infecção de natureza respiratória, podendo ocasionar, especialmente em pessoas classificadas do grupo de risco (idosos, diabéticos, doentes crônicas e outros), uma Síndrome Respiratória Aguda Grave - SRAG² -, dentre outros efeitos, como mialgia, febre, tosse, por exemplo. Tais complicações fazem com que se necessite de atendimento especializado na área da saúde, geralmente, em leitos de Unidades de Tratamento Intensivo - UTI - para reestabilização do quadro agudo e para utilização de respiradores mecânicos.

No Brasil, em virtude das infecções pelo novo coronavírus no país, percebe-se em diversos Estados, como o Rio Grande do Norte, São Paulo, Amazonas, Rio de Janeiro e outros, a superlotação no Sistema Único de Saúde - SUS -, de modo que o atendimento às pessoas acometidas pelo vírus está gerando um colapso ante essa realidade sanitária. De acordo com o levantamento realizado pelo Conselho Nacional de Secretários de Saúde - CONASS, no Painel CONASS³, e no site COVID-19: Painel do Coronavírus ${ }^{4}$ - do Ministério da Saúde, até 22 de julho de 2020, o país registrou um total de 2.227.5I4 casos e 82.77I óbitos (CONASS, 2020; BRASIL, 2020d). É possível evidenciarmos a sua alta capacidade infecciosa, uma vez que o primeiro caso registrado no país foi no final de fevereiro de 2020 e a primeira morte em março de 2020.

Diante desse cenário, em 20 de março de 2020 foi promulgado o Decreto Legislativo ${ }^{5}$ n. 6

\footnotetext{
${ }^{2}$ Entende-se por Síndrome Respiratória Aguda Grave quando um indivíduo apresenta a combinação de sintomas como febre alta, tosse ou dor de garganta, dificuldade respiratória e necessidade de hospitalização (BASTOS et al, 2020).

${ }^{3}$ Levantamento realizado com base nos dados fornecidos pelas Secretarias Estaduais de Saúde. Para visualizar o Portal CONASS, acesse: http://www.conass.org.br/painelconasscovid I 9/

${ }^{4}$ Levantamento realizado com base nos dados registrados pelo Ministério da Saúde. Para visualizar o site, acesse: https://covid.saude.gov.br/

${ }^{5}$ Para leitura do documento na íntegra, acesse: http://www.in.gov.br/en/web/dou/-/decreto-legislativo-249090982

Olhar de professor, Ponta Grossa, v. 24, p. I-9, e-15857.047, 2021.

Disponível em <https://revistas2.uepg.br/index.php/olhardeprofessor>
} 
(BRASIL, 2020a) pelo Senado Federal'b, a ocorrência de calamidade pública nacional. Partindo-se dessa situação, Estados e Municípios, a exemplo da realidade internacional, tomaram medidas de precaução para a redução da infecção, tais como o fechamento do comércio, de instituições educacionais, shoppings centers, bares, restaurantes e outros, por meio de decretos (SÃO PAULO, 2020; RIO DE JANEIRO, 2020; RIO GRANDE DO NORTE, 2020). Em algumas localidades, também foram adotados protocolos de isolamento total por períodos determinados, conhecido como lockdown ${ }^{7}$ (MARANHÃO, 2020).

Além disso, foram criadas alternativas de monitoramento e de acompanhamento de evolução dos casos para a reabertura gradual da economia, para os estabelecimentos de serviços não essenciais e que gerem pouca aglomeração. Entretanto, cabe ressaltar que, segundo o Boletim Epidemiológico Especial do Centro de Operações de Emergência em Saúde Pública - Doença COVID-19 disponibilizado pelo governo federal (BRASIL, 2020b), as Regiões Centro-Oeste e Sul são as que possuem menor incidência de casos e complicações decorrentes do coronavírus

Contudo, mesmo as regiões que possuem uma evolução menor da disseminação viral, em todo o país, o retorno às instituições de ensino ainda não está permitido de modo presencial, podendo-se somente se proceder à realização de atividades pedagógicas por meio remoto. Sendo assim, o contexto educacional viu-se frente a um novo cenário constituído por um contexto pandêmico - a importância da utilização das tecnologias digitais como promotoras da copresença para o desenvolvimento do processo de ensino-aprendizagem. Alternativas como videoconferências, utilização de grupos por redes sociais, aulas via aplicações síncronas e assíncronas começaram a fazer parte dessa "nova normalidade educativa".

Entretanto, cabe salientar que esse novo paradigma, iniciado em escala global, no contexto brasileiro está mais presente na realidade das instituições privadas, uma vez que a dificuldade do acesso à internet pela população da educação pública ainda é um desafio para sua efetividade. De acordo com - Instituto Brasileiro de Geografia e Estatística, cerca de $40 \%$ dos domicílios possuem acesso à internet e 58\% dos brasileiros têm smartphones conectados à rede (IBGE, 2019). Contudo, o foco aqui está na discussão das potencialidades dessa "nova normalidade educativa", abrindo possibilidades para reflexões sobre os desafios inerentes às tecnologias digitais em futuros trabalhos.

\footnotetext{
${ }^{6}$ Foi reconhecido e aprovado pelo Senado a solicitação (Mensagem n. 93) da Presidência da República enviada à instituição em 18 de março.

${ }^{7}$ O lockdown corresponde ao fechamento total dos serviços, espaços públicos, bem como das fronteiras e realização de controle de segurança, viabilidade e circulação de pessoas. Permite-se, somente a circulação para a realização de serviços considerados essenciais - saúde e alimentação, por exemplo -, a depender de cada realidade que foi decretado.
}

Olhar de professor, Ponta Grossa, v. 24, p. I-9, e-15857.047, 2021.

Disponível em <https://revistas2.uepg.br/index.php/olhardeprofessor> 
Diante do exposto, este ensaio de natureza qualitativa teve por objetivo refletir sobre as potencialidades das videoconferências frente à pandemia da COVID-19 no âmbito educacional. De acordo com Meneghetti (20II), o ensaio é uma produção acadêmica que valoriza o processo analíticointerpretativo do pesquisador, assim como a defesa de argumentos frente a um determinado tema, com maior "leveza" no estilo da escrita acadêmica, mas preconizando o rigor científico. Nesse sentido, apresento na próxima seção uma discussão sobre a temática em tela.

\section{Videoconferências no cenário hodierno}

Na contemporaneidade, a inserção das tecnologias digitais da informação e comunicação TDIC - no cotidiano da sociedade do conhecimento é inegável. Pesquisas das diferentes áreas do saber - ciências exatas, ciências sociais e aplicadas, humanidades, por exemplo - vêm, nesta direção, discutindo sobre o papel que elas exercem no contexto sociocultural, econômico e político, bem como suas potencialidades para as demandas do século XXI (HABOWSKI; CONTE, 20I9; SCHLEMMER, 2014).

No contexto educacional, também se está evidenciando, nas últimas décadas, suas potencialidades e necessidade de incorporação ao processo de ensino-aprendizagem, à práxis docente, bem como nas ações de gestão e governança na educação básica e superior (MORAN, 20I7). Reflexões sobre a utilização das tecnologias digitais como ferramentas estratégicas para a formação do estudante, experiências de boas práticas de ensino, de metodologias ativas como promotoras de aprendizagens significativas, assim como análises dos impactos na trajetória discente são pontos que estão ganhando destaque na produção e socialização do conhecimento científico educacional.

De acordo com Habowski e Conte (2019), as tecnologias digitais estão incorporando-se às práticas sociais e no contexto contemporâneo, de modo que a educação e a formação de professores precisam visualizá-las como potenciais ferramentas para o desenvolvimento estudantil ao longo da trajetória educacional. Lévy (2009) anunciava as tecnologias como um "novo mundo" a ser incorporado pela sociedade, por meio de uma cibercultura digital e que, por elas, se pudesse refletir as novas demandas do mundo moderno e, por isso, o ambiente escolar e acadêmico precisava considerar sua introjeção no processo de ensino-aprendizagem.

Moran (2017) destaca que as tecnologias digitais são importantes para a aprendizagem discente e para a formação docente, de modo que, mediante ações didático-pedagógicas, ferramentas tecnológicas constituam uma competência no contexto educacional. Para o autor, a associação dos recursos tecnológicos com a aplicação de metodologias ativas são estratégias importantes para $\circ$ desenvolvimento escolar e acadêmico.

Não obstante, nas últimas décadas, mesmo que as tecnologias integrassem a realidade 
educativa, as relações de ensino e da aprendizagem em contexto macro não tiveram tanta projeção e modificação no ethos educativo. É dizer que muitas ações foram e estão sendo realizadas por meio da utilização das tecnologias digitais, mas repercussões efetivas nos sistemas de ensino ainda são obstáculos enfrentados na atualidade. Apesar disso, a partir da elaboração da Base Nacional Comum Curricular (BRASIL, 20I7), se traz com maior avidez para o cenário brasileiro, por meio desse dispositivo legal, o desenvolvimento do pensamento tecnológico como pressuposto e princípio de ações educativas em toda a educação básica.

Contudo, mesmo que muitas investigações apontem para a importância do papel pedagógico de apoio aos processos educativos que as tecnologias assumem, questões relacionadas às assimetrias presentes no nosso sistema educacional revelam muitos desafios - acesso, percurso, permanência e aprendizagem, por exemplo. Eles, por sua vez, evidenciam problemáticas que transcendem o ambiente educativo, especialmente quando voltamo-nos à realidade da educação pública, haja vista as vulnerabilidades e desigualdades presentes em nosso país.

Diante do exposto, pensarmos na dinâmica emergente no cenário educacional, ante à pandemia de COVID-19, é considerarmos a pluralidade de ações e estratégias que estão sendo realizadas por instituições de ensino para a manutenção das atividades escolares. No caso brasileiro, as ações mais notórias são reveladas por instituições da rede privada que, por sua vez, mantêm o processo de ensinoaprendizagem via utilização de tecnologias digitais pautadas na Portaria $343^{8}$ (BRASIL, 2020c). No trimestre março-junho, vimos estratégias muito frequentes pautadas por videoaulas, videoconferências, utilização de Ambientes Virtuais de Aprendizagens (AVA) e outros.

No que refere à videoconferência, ela está evidenciando à sociedade, nesse período pandêmico, uma oportunidade de aproximação dos diferentes agentes educativos via tele presença ${ }^{9}$, mesmo que distantes geograficamente, possibilitando interações síncronas e em tempo real por diferentes plataformas - ZOOM, Skype, Blue Jeans, Microsoft Teams, Google Meet ${ }^{10}$ e outros. Nessa perspectiva, Domingo e Araújo (20I4, p. 44) afirmam que a videoconferência

\footnotetext{
${ }^{8}$ Portaria Ministerial de 17 de março de 2020, na qual permite que as atividades educacionais presenciais sejam substituídas excepcionalmente por atividades remotas durante o período da pandemia do COVID-19. Para a leitura do documento na íntegra, acesse: http://www.in.gov.br/en/web/dou/-/portaria-n-343-de-17-de-marco-de2020-248564376

${ }^{9}$ Conjunto de tecnologias que permitem que o sujeito sinta-se presente em um determinado ambiente, mesmo estando geograficamente distante.

${ }^{10}$ As plataformas promovem a realização de videoconferências, bem como a apresentação de materiais via compartilhamento de tela com os demais membros da sala. Também pode ser realizado o envio de arquivos, conversas via chat. Na Plataforma Zoom, Blue Jeans, Microsoft Teams e Google Meet, podem ser gerados links de acesso para que pessoas possam acessar à videoconferência.
} 
[...] quando direcionada à área educacional, entre outras peculiaridades, a videoconferência se caracteriza por permitir que os sujeitos que participam do processo de ensino e aprendizagem, dialoguem, mesmo estando em diferentes pontos geográficos, por meio da tecnologia que possibilita que a comunicação bidirecional aconteça com áudio e vídeo em tempo real.

Já Domingo e Araújo (2014) e Cruz (2008) revelam que a videoconferência tem um grande potencial para interações e copresença, uma vez que estudantes e professores possam compartilhar um mesmo ambiente virtual de aprendizagem, mesmo que estejam em lugares geográficos distintos.

Partindo-se desses pressupostos, ao olharmos para a nova realidade que estamos vivendo, me parece evidente o essencial papel que a videoconferência está proporcionando para manutenção das atividades escolares em alguns contextos, bem como potencializada a copresença e uma aproximação dos agentes educativos. Por copresença entende-se sendo a interação realizada por dois ou mais sujeitos em um determinado espaço, mas com realidades diferentes (BACKES; MANTOVANI; BARCHINSKI, 20I7).

Logo, é possível afirmar que, no contexto digital, podemos promover a copresença, quando consideramos que a sala virtual se constituiu como um espaço de interação pelos sujeitos. Nesse sentido, experiências exitosas publicadas recentemente sobre o contexto espanhol referente às videoconferências, via Google Meet, já estão sendo evidenciadas neste cenário da pandemia de COVID19 como espaços em que se percebem a copresença e que, por sua vez, podem trazer inspirações para a realidade brasileira (PERICACHO et al., 2020; SANZ; VICENTE-ROMERO; PRIETO, 2020). Tais experiências revelam as tecnologias como ferramentas de apoio à ação pedagógica e que impactam na aprendizagem discente no contexto virtual.

\section{Considerações finais}

A pandemia do novo coronavírus (COVID-19) trará muitas aprendizagens para a sociedade do século XXI, bem como novas configurações e interações nos diferentes contextos, incluindo o educacional. Em relação à educação, as tecnologias digitais começarão, em larga escala, a integrar de modo efetivo o processo de ensino-aprendizagem, uma vez que poderão ser pensadas diversas alternativas para o desenvolvimento da trajetória escolar e acadêmica dos estudantes e na formação de professores.

Nesse sentido, me parece que as videoconferências, por exemplo, serão incorporadas na "nova normalidade educativa" das instituições de ensino de maneira mais ativa, remodelando as atuais compreensões sobre os espaços de convivência, bem como na minimização da distância entre o presencial e o virtual. A oportunidade que se poderá tirar dessa crise sanitária atual para o contexto educacional é que as tecnologias digitais se mostram como alternativas potenciais, mas não substitutivas

Olhar de professor, Ponta Grossa, v. 24, p. I-9, e-15857.047, 2021.

Disponível em <https://revistas2.uepg.br/index.php/olhardeprofessor> 
e sim complementárias, para a promoção do ensino-aprendizagem em todas as etapas educativas.

Entretanto, mesmo que se introjete a importância das videoconferências e das tecnologias digitais no contexto educacional, de nada contribuirá se não se promoverem as condições necessárias para que todos os estudantes - de escolas públicas e privadas - tenham equidade no acesso tecnológico, visando proporcionar uma formação mais alinhada com as demandas atuais.

\section{Referências}

BACKES, L.; MANTOVANI, A. M.; BARCHINSKI, K. Educação superior em espaços híbridos: a presença e a copresença no processo de cooperação. Conjectura Filos. Educ., Caxias do Sul, v. 22, n. 3, p. 458-48I, set./dez. 2017. DOI: http://I0.18226/2I7846I2.v22.n3.4

BASTOS, L. S. et al. COVID-19 e hospitalizações por SRAG no Brasil: uma comparação até a $12^{\mathrm{a}}$ semana epidemiológica de 2020. Cadernos de Saúde Pública, Rio de Janeiro, v. 4, n. 36, p. I-8, abr. 2020. DOI: https://doi.org/I0.1590/0102-3 IIX00070120

BRASIL. Base nacional comum curricular. Brasília: MEC, 2017. Disponível em: http://basenacionalcomum.mec.gov.br/images/BNCC20dezsite.pdf. Acesso em: 5 jun. 2020.

BRASIL. Decreto legislativo n. 6, de 20 de março de 2020. Brasília: SF, 2020a. Disponível em: http://www.in.gov.br/en/web/dou/-/decreto-legislativo-249090982. Acesso em: 4 jun. 2020.

BRASIL. Boletim epidemiológico especial COE-COVIDI9 - n. 17. Brasília: COE, 2020b. Disponível em: https://www.saude.gov.br/images/pdf/2020/May/29/2020-05-25---BEE I7---Boletim-doCOE.pdf. Acesso em: 5 jun. 2020.

BRASIL. Portaria n. 343, de 17 de março de 2020. Brasília: MEC, 2020c. Disponível em: http://www.in.gov.br/en/web/dou/-/portaria-n-343-de-I7-de-marco-de-2020-248564376. Acesso em: 4 jun. 2020.

BRASIL. Ministério da Saúde. COVID-19: Painel Coronavírus. Brasília: MS, 2020d. Disponível em: https://covid.saude.gov.br/ Acesso em: 22 jul. 2020.

CONSELHO NACIONAL DE SECRETÁRIOS DE SAÚDE. Painel CONASS. Brasília: CONASS, 2020. Disponível em: http://www.conass.org.br/painelconasscovidI9/. Acesso em: 22 jul. 2020.

CRUZ, D. M. A construção do professor midiático: o docente comunicador na educação a distância por videoconferência. Cadernos de Educação, Pelotas, v. 30, p. 20I-2 I4, jan./jun. 2008. Disponível em: https://periodicos.ufpel.edu.br/ojs2/index.php/caduc/article/view/I77I. Acesso em: 5 jun. 2020.

DOMINGO, R. P.; ARAÚJO, M. A. S. Videoconferências na educação a distância: reflexões sobre o potencial pedagógico desta ferramenta. Educação \& Linguagem, São Paulo, v. 17, n. 2, p. 38-53, jul./dez. 20 I4. DOI: http://dx.doi.org/I0.15603/2 I76-I043/el.vI7n2p38-53

HABOWSKI, A. C.; CONTE, E. (Re)pensar as tecnologias na educação a partir da teoria crítica. São Paulo: Pimenta Cultural, 2019.

INSTITUTO BRASILEIRO DE GEOGRAFIA E ESTATIÍSTICA. Síntese dos indicadores sociais: uma

Olhar de professor, Ponta Grossa, v. 24, p. I-9, e-15857.047, 202 I.

Disponível em <https://revistas2.uepg.br/index.php/olhardeprofessor> 
análise das condições de vida da população brasileira 2019. Rio de Janeiro: IBGE, 2019.

LÉVY, P. Cibercultura. Tradução de Carlos Irineu da Costa. São Paulo: 34, 2009.

MARANHÃO. Decreto n. 35.784, de 03 de maio de 2020. São Luís: DOEMA, 2020. Disponível em: https://www.ma.gov.br/agenciadenoticias/wp-content/uploads/2020/05/DECRETO-35.784-DE-3DE-MAIO-DE-2020.pdf. Acesso em 7 jun. 2020.

MENEGHETTI, F. K. O que é um ensaio-teórico? Rev. Adm. Contemp., Curitiba, v. I5, n. 2, p. 320332, abr. 20Il. Disponível em: <http://www.scielo.br/scielo.php?script=sci_arttext\&pid=SI4I5655520II0002000I0\&lng=en\&nrm=iso>. Acesso em: 9 jul. 2020. DOI: https://doi.org/I0.1590/SI4I5-655520II000200010

MORAN, J. Metodologias ativas e modelos híbridos na educação. In: YAEGASHI, S. et al. (Orgs.). Novas tecnologias digitais: reflexões sobre mediação, aprendizagem e desenvolvimento. Curitiba: CRV, 2017.

PERICACHO, M. et al. Experiencias de Docencia Virtual en Facultades de Medicina Españolas durante la pandemia COVID-19: Anatomía, Fisiología, Fisiopatología, Oncología. Revista Española de Educación Médica, Múrcia, Espanha v. I, p. 32-39, 2020. DOI: http:// 10.60 I8/edumed.42493 I

RIO DE JANEIRO. Decreto n. 47.102, de 01 de junho de 2020. Rio de Janeiro: DOERJ, 2020. Disponível em: https://pge.rj.gov.br/comum/code/MostrarArquivo.php?C=MTEwMzg\%2C. Acesso em: 7 jun. 2020.

RIO GRANDE DO NORTE. Decreto n. 29.742, de 04 de junho de 2020. Natal: DOERN, 2020. Disponível em: http://diariooficial.rn.gov.br/dei/dorn3/docview.aspx?id_jor $=0000000$ I \&data $=20200604 \&$ \&d_doc $=6852$ 95. Acesso em: 7 jun. 2020.

SANZ, E.; VICENTE-ROMERO, J.; PRIETO, A. Experiencias de Docencia Virtual en Facultades de Medicina Españolas durante la pandemia COVID-19 (II): Farmacología, Imunología. Revista Española de Educación Médica, Múrcia, Espanha, v. I, p. 74-8I, 2020. DOI: http://I0.60 I8/edumed.42948

SÃO PAULO. Decreto n. 64.994, de 28 de maio de 2020. São Paulo: DOESP, 2020. Disponível em: http://www.pge.sp.gov.br/acompanhe/covid/arquivo/DecretoN64994.pdf. Acesso em: 7 jun. 2020.

SCHLEMMER, E. Gamificação em espaços de convivência híbridos e multimodais: design e cognição em discurso. Revista da FAEEBA - Educação e Contemporaneidade, Salvador, v. 42 n. 23, p. 73 89, jul./dez. 20I4. DOI: http://dx.doi.org// 0.2I879/faeeba2358-0I94.20I4.v23.n42.p\%25p

Recebido em: 09 de junho de 2020.

Versão corrigida recebida em: 23 de julho de 2020.

Aceito em: 19 de agosto de 2020.

Publicado online em: 28 de maio de 202I.

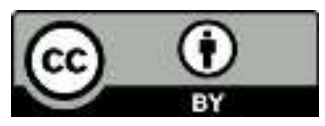

Olhar de professor, Ponta Grossa, v. 24, p. I-9, e-15857.047, 202 I.

Disponível em <https://revistas2.uepg.br/index.php/olhardeprofessor> 